УДК 54.057

ИСПЫТАНИЕ ПЛАТИНОСОДЕРЖАЩЕГО ЦЕОЛИТНОГО

КАТАЛИЗАТОРА В ПРОЦЕССЕ СРЕДНЕТЕМПЕРАТУРНОЙ ИЗОМЕРИЗАЦИИ ВЫСОКОСЕРНИСТОГО СЫРЬЯ

\title{
TESTING OF A PLATINUM-CONTAINING ZEOLITE CATALYST IN THE PROCESS OF MEDIUM-TEMPERATURE ISOMERIZATION OF HIGH-SULFUR FEEDSTOCK
}

\author{
Калягин К.А., Давлетшин А.Р., Гаеткулова Г.К., Пэн Кэ, \\ Шадрина А.Э.
}

Уфимский государственный нефтяной технический университет, г. Уфа, Российская Федерация

\author{
K.A. Kaliagin, A.R. Davletshin, G.K. Gaetkulova, Pen Ke, \\ A.E. Shadrina \\ Ufa State Petroleum Technological University, \\ Ufa, Russian Federation \\ e-mail: kirilll55@yandex.ru
}

Аннотация. В работе приведены результаты испытания платиносодержащего цеолитного катализатора в процессе среднетемпературной изомеризации пентановой фракции с повышенным содержанием сернистых соединений.

В процессе испытания катализатора в качестве сырья использовались пентановые фракции с различным содержанием серы (низкосернистая и высокосернистая). Применение низкосернистого сырья позволило определить оптимальную температуру процесса в диапазоне $240-280{ }^{\circ} \mathrm{C}$.

C изменением температуры в данных пределах конверсия увеличивается с 30 \% масс. до 70 \% масс., дальнейшее повышение 
температуры приводит к значительному увеличению доли побочных реакций.

Рост селективности по $i$-пентану наблюдается до температуры $260{ }^{\circ} \mathrm{C}$, a с дальнейшим повышением температуры резко снижается доля целевого продукта в изомеризате. Для проведения испытания на высокосернистой пентановой фракции была принята температура $260{ }^{\circ} \mathrm{C}$, при которой наблюдалось максимальное значение селективности. Исследование на стабильность работы катализатора на высокосернистом сырье проводилось при тех же условиях, что и на низкосернистом.

C помощью методов газожидкостной хроматографии, рентгенофлуоресцентной спектрометрии и дифференциальнотермического анализа определены физико-химические характеристики сырья и продукта, технологические показатели активности катализатора и установлено, что катализатор обеспечивает высокие конверсию и селективность по $i$-пентану в условиях процесса среднетемпературной изомеризации пентановой фракции и характеризуется относительно высокой стабильностью в присутствии высокого содержания серы.

Еще одной отличительной особенностью катализатора является его способность инициировать реакции гидрообессеривания с образованием сероводорода. В результате содержание серы в изомеризате уменьшается, а сероводород выводится с газовыми продуктами процесса изомеризации.

Abstract. The results of testing of a platinum-containg zeolite catalyst in the process of medium-temperature isomerization of high-sulfur pentane fraction, are shown.

In the process of testing the catalyst, pentane fractions with different sulfur content (low-sulfur and high-sulfur) were used as feedstock. The use of lowsulfur raw materials made it possible to determine the optimum process temperature in the range $240-280{ }^{\circ} \mathrm{C}$. With a change in temperature within this range, the conversion increases from $30 \%$ to $70 \%$ by weight, further increase in temperature leads to a significant increase in the proportion of adverse reactions. 
The increase in selectivity for $i$-pentane is observed up to a temperature of $260{ }^{\circ} \mathrm{C}$, and with a further increase in temperature, the proportion of the desired product in isomerate is sharply reduced. To test the high-sulfur pentane fraction, a temperature of $260{ }^{\circ} \mathrm{C}$ was adopted, at which the maximum selectivity was observed. A study on the operation stability of the catalyst on high-sulfur feedstocks was carried out under the same conditions as for low-sulfur feedstocks.

Using methods of gas-liquid chromatography, $\mathrm{x}$-ray fluorescence spectrometry and differential thermal analysis, the physicochemical characteristics of the feed and product, technological parameters of the catalyst activity have been defined. It has been found that the catalyst provides high conversion and $i$-pentane selectivity in the conditions of medium-temperature isomerization of pentane fraction, and it is marked by a relatively high stability in the presence of high sulfur content.

Another distinguishing feature of the catalyst is its ability to initiate hydrodesulfurization reactions to form hydrogen sulphide. As a result, the sulfur content of the isomerate decreases, and the hydrogen sulphide is removed from the gas products of the isomerization process.

Ключевые слова: изомеризация, катализатор, пентановая фракция, содержание серы, устойчивость К сернистым соединениям, дифференциально-термический анализ, изомеризат, конверсия, селективность.

Keywords: isomerization, catalyst, pentane fraction, sulfur content, sulfur resistance, differential thermal analysis, isomerate, conversion, selectivity.

\section{Введение}

Изомеризация является одним из наиболее экономически выгодных процессов получения высокооктановых компонентов бензинов. 
Эффективность процесса определяется не только типом технологии (низко-, средне-, высокотемпературная), но и выбором применяемого катализатора [1].

Скелетная изомеризация углеводородов протекает почти без изменения объема, с небольшим выделением теплоты (2-20 КДж/моль). Поэтому в смеси «алканы - изоалканы» на термодинамическое равновесие влияет только температура процесса.

Повышение температуры смещает равновесие в сторону линейных парафинов, снижение температуры способствует образованию более разветвленных изомеров, обладающих высокими октановыми числами. При этом содержание разветвленных структур в изомеризате при одной и той же температуре процесса повышается с увеличением молекулярной массы парафина [2].

В современных бифункциональных катализаторах, обладающих гидрирующими/дегидрирующими функциями, применяют такие металлы как палладий и платина, а в качестве носителя - фторированный или хлорированный оксиды алюминия и цеолиты [3], которые также придают кислотную функцию катализатору. В зависимости от марки катализатора процесс изомеризации делится на следующие виды: высокотемпературная (360-420 $\left.{ }^{\circ} \mathrm{C}\right)$, среднетемпературная (230280 $\left.{ }^{\circ} \mathrm{C}\right)$ и низкотемпературная (100-150 С) изомеризация [4].

В [5] изучены условия и эффективность работы существующих катализаторов изомеризации, причины и время их дезактивации. Представлены результаты влияния гетеропримесей в исходном сырье на стабильную работу катализатора. Вследствие этого актуальным остается вопрос об устойчивой работе катализаторов в присутствии нежелательных компонентов.

В ходе эксплуатации катализатора его активность снижается за счет действия двух факторов: отложения кокса на поверхности катализатора и отравления сернистыми соединениями [6]. 
Дезактивация катализаторов в результате адсорбции высокомолекулярных соединений - обратимый процесс, то есть при удалении продуктов уплотнения каталитические свойства восстанавливаются. Но действие серосодержащих углеводородов необратимо дезактивирует катализаторы, в состав которых входит оксид алюминия.

Механизм катализа в процессе изомеризации основан на спилловере водорода. Транспорт протона $\mathrm{H}+$ между кислотными центрами катализатора и молекулой н-пентана обеспечивает существование кислотных центров Льюиса (ЛКЦ) и Бренстеда (БКЦ). При попадании сероорганических соединений на катализатор происходит активация молекул и ЛКЦ дезактивируются молекулами водорода, происходит прекращение существования ЛКЦ, а, следовательно, не образуются БКЦ нарушается механизм спилловера водорода. Далее молекулярный водород сорбируется на платине и переводит её в неактивное состояние нарушаются гидрирующие/дегидрирующие функции катализатора. Также молекула сероорганического соединения разрушает поверхность катализатора.

Отдавая ему энергию, сера переводит активные тетраэдры $\mathrm{AlO}^{-}{ }^{-}$ неактивные октаэдры $\mathrm{AlO6}^{-}$[7]. Вследствие этого снижается энергия активации коалесценции платины, и частицы начинают укрупняться [8], перекрывая кислотные центры [9].

Действие сернистых соединений нарушает механизм катализа, из-за чего долгая эксплуатация таких катализаторов на высокосернистом сырье невозможна.

\section{Экспериментальная часть}

В исследовании процесса среднетемпературной изомеризации сырья с повышенным содержанием сернистых соединений использовался промышленно производимый платино-содержащий катализатор, 
носителем в котором является цеолит структуры морденит в водородной форме. Физико-химические характеристики катализатора приведены в таблице 1.

Таблица 1. Физико-химические свойства катализатора среднетемпературной изомеризации

\begin{tabular}{|l|c|}
\hline \multicolumn{1}{|c|}{ Показатель } & Значение \\
\hline Цеолит - морденит: & $70-75$ \\
\hline - массовая доля $\mathrm{SiO}_{2}, \%$ & $25-30$ \\
\hline - массовая доля $\mathrm{Al}_{2} \mathrm{O}_{3}, \%$ & $0,1-1,0$ \\
\hline Содержание платины, \% масс. & $600-650$ \\
\hline Насыпная плотность, кг/м³ & \\
\hline
\end{tabular}

В качестве сырья процесса использовались пентановые фракции с различным содержанием сернистых соединений. Анализ содержания общей серы проводился методом рентгенофлуоресцентной спектрометрии (EDXRF) с помощью прибора RX-60SH. Характеристика сырья приведена в таблицах 2 и 3.

Процесс среднетемпературной изомеризации проводился на установке проточного типа. Экспериментальная установка предназначена для исследования процессов, протекающих в условиях повышенного давления в проточном режиме, при максимальном давлении 10 МПа и максимальной температуре $700{ }^{\circ} \mathrm{C}$. Схема установки приведена на рисунке 1 .

Таблица 2. Характеристика фракции низкосернистой пентановой фракции

\begin{tabular}{|l|c|}
\hline \multicolumn{1}{|c|}{ Наименование показателей } & Значение, \% масс. \\
\hline Сумма углеводородов $\mathrm{C}_{4}$, не более & 0,05 \\
\hline Нормальный пентан, не менее & 94,69 \\
\hline Изопентан & 4,36 \\
\hline Сумма углеводородов $\mathrm{C}_{6}$ и выше, не более & 0,90 \\
\hline Содержание серы & 0,00035 \\
\hline
\end{tabular}


Таблица 3. Характеристика высокосернистой пентановой фракции

\begin{tabular}{|l|c|}
\hline \multicolumn{1}{|c|}{ Наименование показателей } & Значение, \% масс. \\
\hline Сумма углеводородов $\mathrm{C}_{4}$, не более & 0,03 \\
\hline Нормальный пентан, не менее & 99,68 \\
\hline Изопентан & 0,18 \\
\hline Сумма углеводородов $\mathrm{C}_{6}$ и выше, не более & 0,15 \\
\hline Содержание серы & 0,016 \\
\hline
\end{tabular}

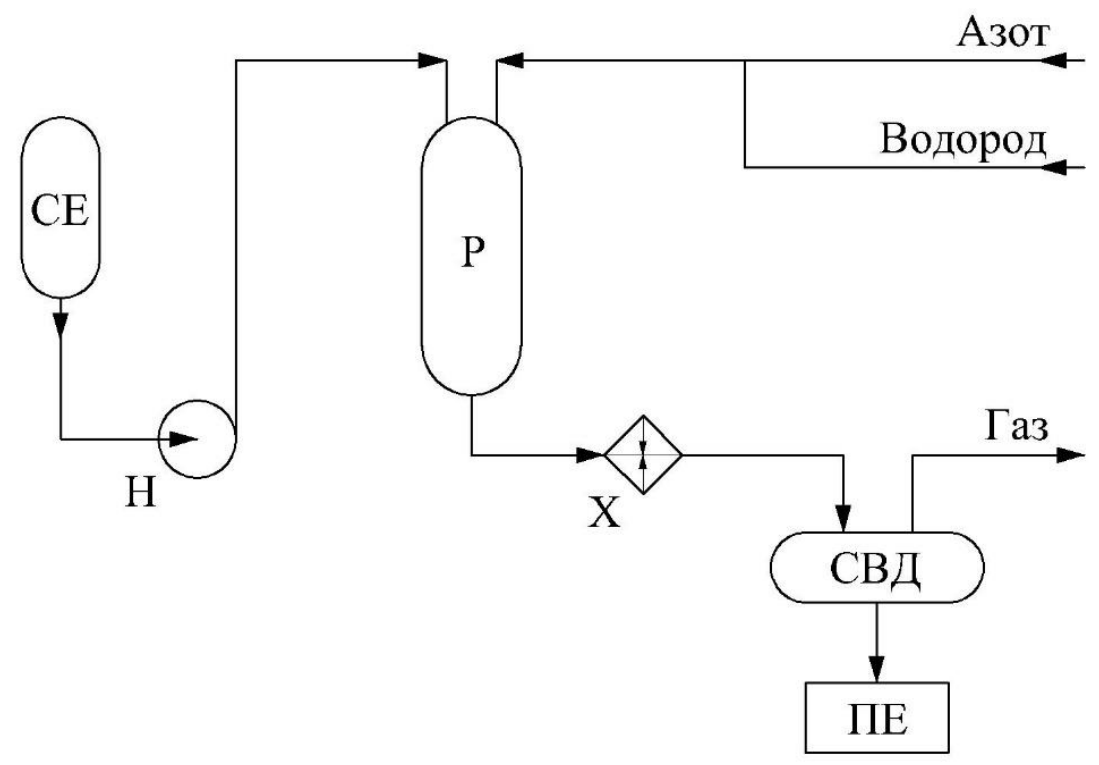

СЕ - сырьевая емкость; $\mathrm{H}$ - насос;

$\mathrm{P}$ - реактор; $\mathrm{X}$ - холодильник;

СВД - сепаратор высокого давления; ПЕ - Приемная емкость

Рисунок 1. Схема экспериментальной установки

Азот в процессе необходим для продувки системы, опрессовки и проверки системы на герметичность. Водород используется для подавления реакций коксообразования и образования продуктов дегидрирования, для поддержания активности кислотных центров катализатора и удаления серы из реакционной смеси.

Сырье из емкости СЕ подается жидкостным насосом Н, работающим без пульсаций, в реактор с рубашкой, выполняющей роль печи, куда одновременно подается водород. 
Блок разделения продуктов состоит из обратного холодильника и сепаратора высокого давления.

Конденсат после разделения продуктов в сепараторе высокого давления сливается в приемную емкость (ПЕ). Газообразные продукты из сепаратора высокого давления (СВД) направляются в вытяжную вентиляцию.

Применение низкосернистого сырья необходимо для определения оптимальной температуры процесса в диапазоне $240-280^{\circ} \mathrm{C}$. Неизменными параметрами оставались давление 3 МПа, объемное соотношение водород : сырье $-500: 1$.

Завершение испытания при той или иной температуре определялось по снижению активности катализатора и уменьшению значения октанового числа изомеризата, после чего проводилось увеличение температуры в реакторе до $280{ }^{\circ} \mathrm{C}$ с шагом в $10{ }^{\circ} \mathrm{C}$. Расход сырья и объемное соотношение водород : сырье оставались на прежнем уровне.

Отбираемые пробы анализировались с помощью метода газожидкостной хроматографии в изотермическом режиме на приборе Хроматек Кристалл 5000.1.

Комплексный термический анализ образцов свежего и испытанного катализатора проводили на установке Thermoscan-2, предназначенной для определения температур и оценке теплоты фазовых переходов и других процессов, связанных с выделением или поглощением тепла (дифференциально-термический анализ (ДТА)), а также для определения температуры и величины потери веса испытанного образца в процессе нагрева (термогравиметрический анализ (ТГА)). Эксперименты проводились в интервале температур $20-700{ }^{\circ} \mathrm{C}$ в открытом кварцевом сосуде в воздушной среде; скорость нагрева образца $10{ }^{\circ} \mathrm{C} /$ мин. 


\section{Обсуждение результатов}

C изменением температуры в пределах $240-280{ }^{\circ} \mathrm{C}$ конверсия увеличивается с 30 до 70 \% масс. (рисунок 2), дальнейшее повышение температуры приводит к значительному увеличению доли побочных реакций.

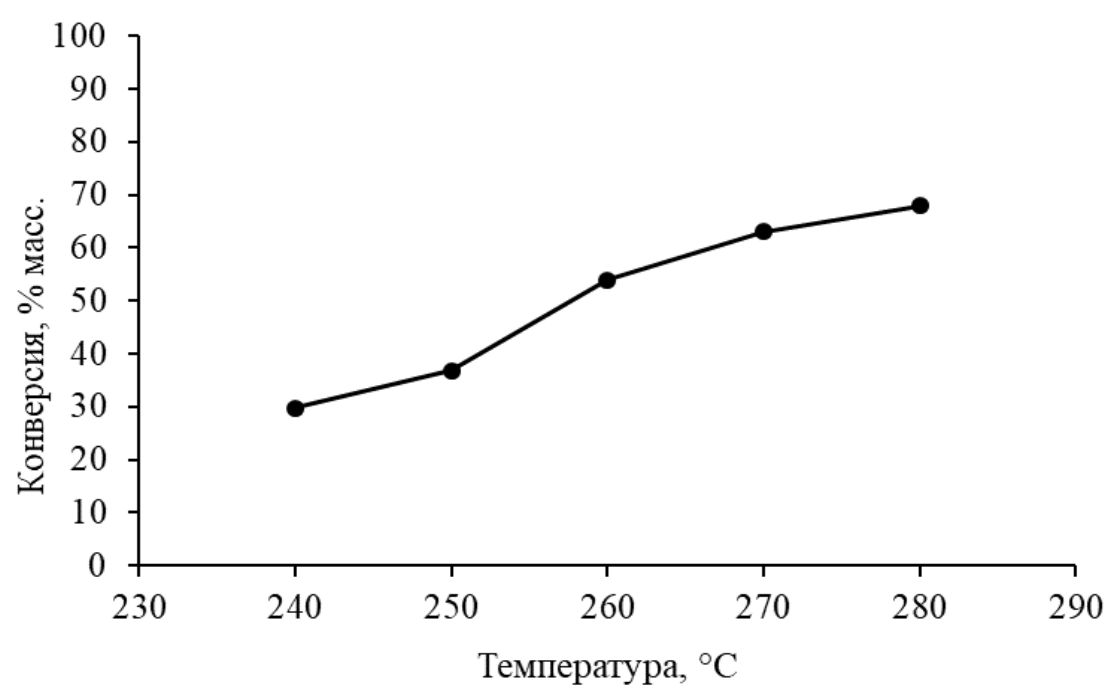

Рисунок 2. Зависимость конверсии от температуры в процессе изомеризации низкосернистого сырья

Рост селективности по $i$-пентану (рисунок 3) наблюдается до температуры $260{ }^{\circ} \mathrm{C}$, а при дальнейшем повышении температуры резко снижается доля целевого продукта в изомеризате.

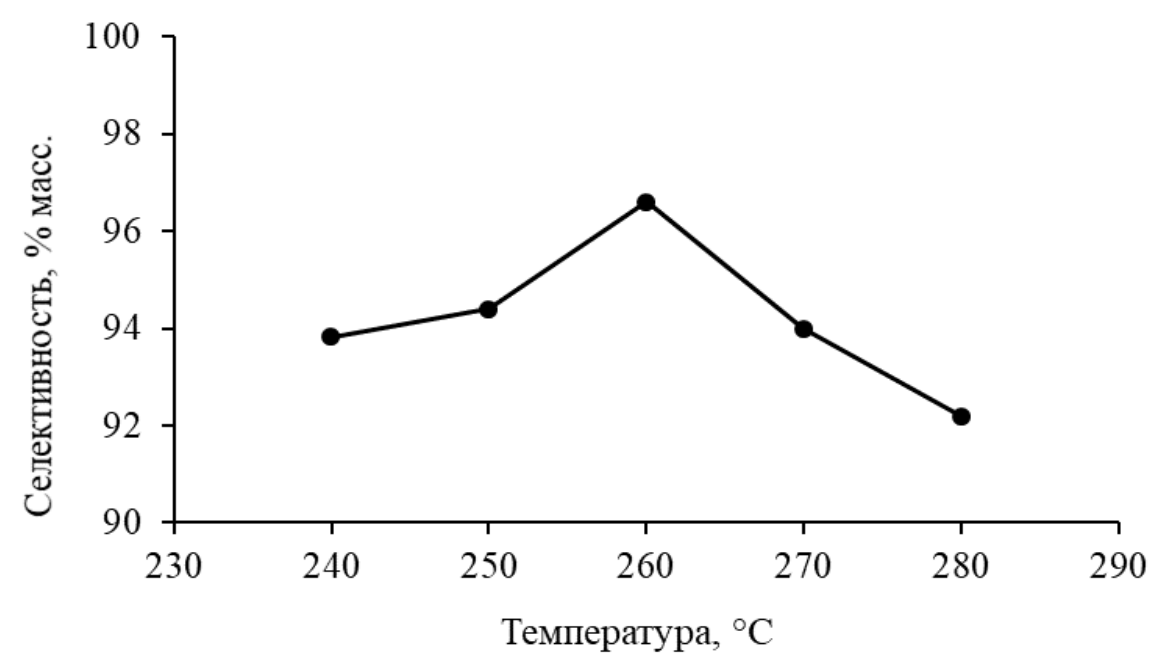

Рисунок 3. Зависимость селективности по $i$-пентану от температуры в процессе изомеризации низкосернистого сырья 
Для проведения испытания на высокосернистой пентановой фракции была принята температура $260{ }^{\circ} \mathrm{C}$, при которой наблюдались максимальное значение селективности 96,6 \% масс. и значение конверсии $53,9 \%$ мacc.

Далее проводилось исследование на стабильность работы катализатора при давлении 3 МПа, объемном соотношении водород : сырье - $500: 1$, температуре $260^{\circ} \mathrm{C}$ при работе на высокосернистом сырье.

Исследование в течение 140 ч показало (рисунок 4), что катализатор проявляет высокую активность и стабильную работу на протяжении всего времени испытания.

Изменения селективности и конверсии от времени поддерживаются на уровне 94 - 96 \% масс. и 62 - 66 \% масс. соответственно, что указывает на устойчивость катализатора к сере и возможность его применения на производствах без предварительного обессеривания сырья.

Другой отличительной особенностью катализатора является его способность инициировать реакции гидрообессеривания с образованием сероводорода.

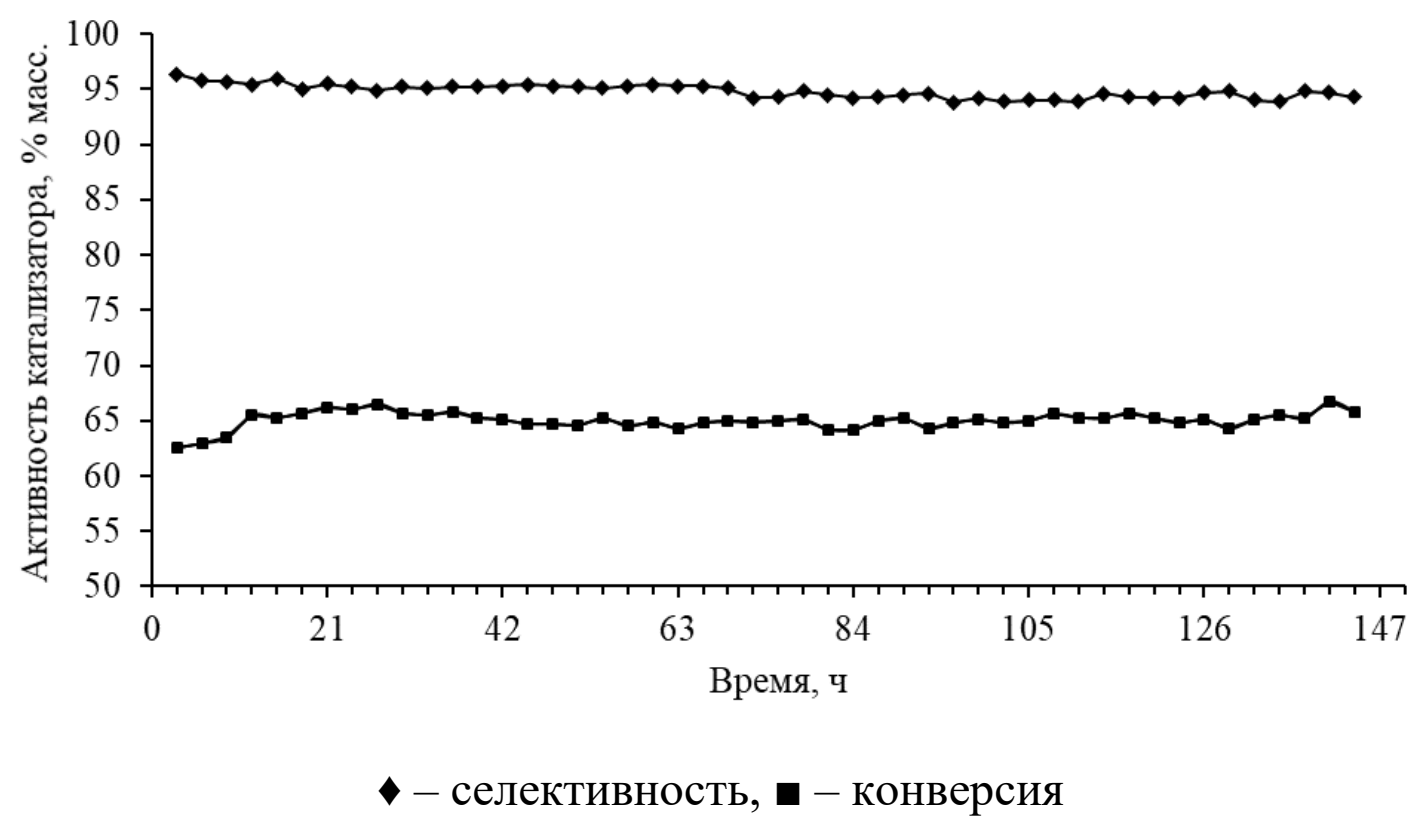

Рисунок 4. График изменения показателей активности от времени на высокосернистом сырье 
В результате содержание серы в изомеризате уменьшается от 160 ppm до 10 ppm, а сероводород выводится с газовыми продуктами процесса изомеризации.

Далее с помощью прибора Thermoscan-2 была определена степень адсорбции высокомолекулярных соединений на поверхности катализатора. На кривых ДТА (рисунок 5) изображены термограммы свежего и испытанного (кривые 1 и 2) катализаторов.

Установлено, что при температурном интервале 60-100 ${ }^{\circ} \mathrm{C}$ наблюдается эндотермический эффект, обусловленный десорбцией связанной в порах влаги и адсорбцией низкомолекулярных углеводородов.

На полученной кривой ДТА испытанного катализатора (кривая 2) присутствует высокотемпературная область исследования $\left(120-490{ }^{\circ} \mathrm{C}\right)$, в которой наблюдается слабовыраженный экзотермический эффект, связанный с выгоранием высокомолекулярных продуктов уплотнения.

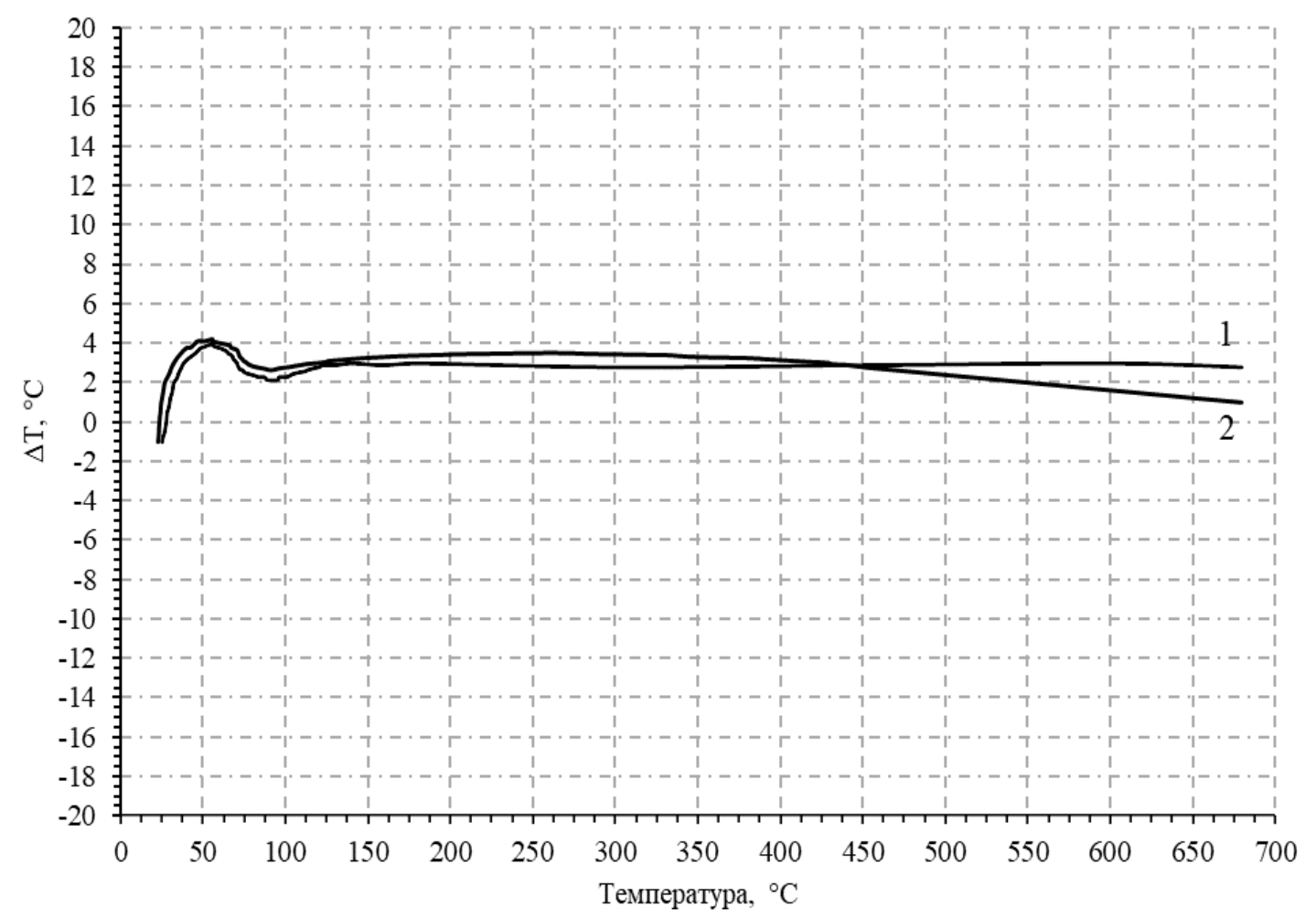

1 - свежий катализатор, 2 - использованный катализатор

Рисунок 5. Кривые ДТА 


\section{Вывод}

Полученные данные показывают, что цеолитный катализатор слабо подвержен дезактивации серой, а, следовательно, проявляет высокую каталитическую активность в присутствии высокосернистого сырья на протяжении длительного срока эксплуатации.

Данный катализатор находит применение не только в нефтеперерабатывающей промышленности при получении высокооктановых компонентов автомобильных бензинов, но и в нефтехимической отрасли с целью получения сырья производства каучука.

Работа проведена в рамках выполнения проектной части государственного задания № 10.1448.2017/4.6.

\section{Список используемых источников}

1. Строкин А.В., Черкасова Е.И. Основные тенденции процесса изомеризации // Вестник Казанского технологического университета. 2014. № 8. С. 66-68.

2. Ясакова Е.А., Ситдикова А.В., Ахметов А.Ф. Тенденции развития процесса изомеризации в России и за рубежом // Нефтегазовое дело. 2010. № 1.19 c. URL: http://ogbus.ru/files/ogbus/authors/Yasakova/Yasakova_1.pdf.

3. Гизетдинова А.Ф., Киселева Т.П., Посохова О.М., Резниченко И.Д., Юрьев М.Ю., Скорникова С.А. Современные катализаторы ОАО АЗКиОС для процессов изомеризации и гидродепарафинизации // Катализ в промышленности. 2014. № 5. С. 38-43.

4. Пономарева А.Я. Экологические аспекты производства моторных топлив методом изомеризации фракций $\mathrm{C}_{5}-\mathrm{C}_{6} / /$ Научный альманах. 2015. № 10-3 (12). С. 196-199. 
5. Шакун А.Н., Федорова М.Л. Эффективность различных типов катализаторов и технологий изомеризации легких бензиновых фракций // Катализ в промышленности. 2014. № 5. С. 29-37.

6. Уржунцев Г.А., Токтарев А.В., Ечевский Г.В., Делий И.В., Власова Е.Н., Бухтиярова Г.А. Перспективы использования Мо- и W- содержащих катализаторов в процессах гидроизомеризации: обзор патентной информации 1. Катализаторы на основе фосфидов молибдена и вольфрама // Катализ в промышленности. 2015. № 6. С. 47-55.

7. Ламберов А.А., Мухамбетов И.Н., Залялиев Р.Ф. Дезактивация промышленного алюмооксидного катализатора скелетной изомеризации н-бутенов // Катализ в промышленности. 2014. № 1. С. 49-54.

8. Ламберов А.А., Ситникова Е.Ю., Гильмуллин Р.Р., Галимзянова Л.Р., Фомина Е.А. Причины снижения активности катализатора скелетной изомеризации $н$-бутиленов при промышленной эксплуатации // Катализ в промышленности. 2009. № 2. С. 5-6.

9. Крылов О.В. Гетерогенный катализ: учеб. пособие для вузов. М.: ИКЦ «Академкнига», 2004. 679 с.: ил.

\section{References}

1. Strokin A.V., Cherkasova E.I., Osnovnye tendentsii protsessa isomerizatsii // Vestnik Kasanskogo tehnologicheskogo universiteta, 2014, No. 8, pp. 66-68. [in Russian].

2. Yasakova E.A., Sitdikova A.V., Akhmetov A.F. Tendentsii razvitiya protsessa isomerizatysii $\mathrm{v}$ Rossii i za rubezhom [Tendency of Isomerization Process Development in Russia and Foreign Countries]. Neftegazovoe delo - Oil and Gas Business, 2010, No. 1. 19 p. URL: http://ogbus.ru/files/ogbus/authors/Yasakova/Yasakova_1.pdf. [in Russian]. 
3. Gizetdinova A.F., Kiseleva T.P., Posohova O.M., Reznichenko I.D., Yurev M.Yu., Skornikova S.A., Sovremennyye katalizatory OAO AZKiOS dlya protsessov izomerizatsii i gidrodeparafinizatsii. Kataliz v promyshlennosti Catalysis in Industry, 2014, No. 5, pp. 38-43. [in Russian].

4. Ponomareva A.Ia., Ekologicheskie aspekty proizvodstva motornyh topliv metodom izomerizacii frakcii $\mathrm{C}_{5}-\mathrm{C}_{6}$ [Environmental Aspects of Motor Fuels Production Method of Isomerization of $\mathrm{C}_{5}-\mathrm{C}_{6}$ Fractions]. Nauchnyi almanakh Science Almanac, 2015, No. 10-3 (12), pp. 196-199. [in Russian].

5. Shakun A.N., Fedorova M.L., Effektivnost razlichnyh tipov katalizatorov i tehnologii isomerizacii legkih benzinovyh frakcii [Efficiency of Different Catalysts and Technologies for Isomerization of Light Gasoline Fractions]. Kataliz v promyshlennosti - Catalysis in Industry, 2014, No. 5, pp. 29-37. [in Russian].

6. Urzhuncev G.A., Toktarev A.V., Echevskii G.V., Delii I.V., Vlasova E.N., Buhtiiarova G.A., Perspectivy ispolzovaniia Mo- i W-soderzhashchih katalizatorov $\mathrm{v}$ processah gidroizomerizacii: obzor patentnoi informacii [Prospects for Using Mo- and W-Containing Catalysts in Hydroisomerization. A Patent Review. Part 1: Catalysts Based on Molybdenum and Tungsten Phosphides]. Kataliz $v$ promyshlennosti Catalysis in Industry, 2015, No. 6, pp. 47-55. [in Russian].

7. Lamberov A.A., Muhambetov I.N., Zalialiev R.F., Dezactivaciia promyshlennogo alyumooksidnogo katalizatora skeletnoi izomerizacii n-butenov [Decontamination of Industrial Alumina Catalyst for Skeletal Isomerization of N-Butenes]. Kataliz v promyshlennosti - Catalysis in Industry, 2014, No. 1, pp. 49-54. [in Russian]. 
8. Lamberov A.A., Sitnikova E.Yu., Gilmullin R.R., Galimzianova L.R. Fomina E.A., Prichiny snizheniia aktivnosti katalizatora skeletnoi izomerizacii n-butilenov pri promyshlennoi ekspluatacii [Causes of Decrease in Activity of the Catalyst for Skeletal Isomerization of n-Butenes during Commercial Operation]. Kataliz v promyshlennosti - Catalysis in Industry, 2009, No. 2, pp. 5-6. [in Russian].

9. Krylov O.V. Geterogennyi kataliz: Uchebnoe posobie dlya vuzov [Heterogeneous Catalysis: Manual for High Schools]. Moscow, IKTs «Akademkniga», 2004. 679 p. [in Russian].

\section{Сведения об авторах}

\section{About the authors}

Калягин К.А., магистрант кафедры «Технология нефти и газа», ФГБОУ ВО «УГНТУ», г. Уфа, Российская Федерация

K.A. Kaliagin, Undergraduate Student of Oil and Gas Technology Department, FSBEI HE «USPTU», Ufa, Russian Federation

e-mail: kirill155@yandex.ru

Давлетшин А.P., канд. техн. наук, доцент базовой кафедры «Технология нефти и газа», ФГБОУ ВО «УГНТУ», г. Уфа, Российская Федерация

A.R. Davletshin, Candidate of Engineering Sciences, Associate Professor of Oil and Gas Technology Department, FSBEI HE «USPTU», Ufa, Russian Federation

Гаеткулова Г.К., магистрант кафедры «Нефтехимия и химическая технология» ФГБОУ ВО «УГНТУ», г. Уфа, Российская Федерация

G.K. Gaetkulova, Undergraduate Student of Petrochemistry and Chemical Technology Department, FSBEI HE «USPTU», Ufa, Russian Federation 
Пэн Кэ, магистрант кафедры «Технология нефти и газа», ФГБОУ ВО «УГНТУ», г. Уфа, Российская Федерация

Pen Ke, Undergraduate Student of Oil and Gas Technology Department, FSBEI HE «USPTU», Ufa, Russian Federation

Шадрина А. Э., аспирант кафедры «Технология нефти и газа», ФГБОУ ВО «УГНТУ», г. Уфа, Российская Федерация

A.E. Shadrina, Post-graduate Student of Oil and Gas Technology Department, FSBEI HE «USPTU», Ufa, Russian Federation 